\title{
Numerical study on heat transfer between airflow and surrounding rock with two major ventilation models in deep coal mine
}

\author{
Pingye Guo ${ }^{1,2} \cdot \mathrm{Yi} \mathrm{Su}^{1,2} \cdot$ Dongyang Pang ${ }^{1,2} \cdot$ Yanwei Wang ${ }^{3} \cdot$ Zhibiao Guo $^{1,2}$
}

Received: 22 August 2019 / Accepted: 10 July 2020 / Published online: 5 August 2020

(C) The Author(s) 2020

\begin{abstract}
Not only is the thermal environment of the coal mining face related to the temperature of the surrounding rock, it is also closely associated with the ventilation model of the working face. In this study, the numerical methods were applied to study the impact of two major ventilation systems on the airflow temperature of working face in coalmine. Firstly, a heat transfer model of the surrounding rock and airflow was established to reveal that the wall roughness of the surrounding rock could enhance heat transfer between the surrounding rock and the airflow. Moreover, an analysis was conducted of the heat transfer between the airflow and the surrounding rock under different modes of ventilation in the first mining face. According to the analytical results, the temperature of airflow in the U-type ventilation system is lower than in the Y-type ventilation system. For the next adjacent coal mining face, however, the Y-type ventilation system is more conducive in reducing the temperature of the airflow. Therefore, with regard to the mine as a whole, the Y-type ventilation system is more effective than a U-type system in reducing heat and humidity in the ambient environment.
\end{abstract}

Keywords Ventilation $\cdot$ Heat transfer $\cdot$ Deep mine $\cdot$ Hot and humidity environment

\section{Nomenclature}

T Temperature, ${ }^{\circ} \mathrm{C}$

$Q \quad$ Heat, $W$

$k \quad$ Thermal conductivity, $W /\left(\mathrm{m}^{2} \cdot{ }^{\circ} \mathrm{C}\right)$

$v$ Velocity, $\mathrm{m} / \mathrm{s}$

$h \quad$ Heat transfer coefficient, $\mathrm{W} /\left(\mathrm{m}^{2} \cdot{ }^{\circ} \mathrm{C}\right)$

$p$ Pressure, $\mathrm{Pa}$

$t$ Time, $s$

\section{Greek symbols}

$\alpha$ Thermal diffusivity, $\mathrm{m}^{2} / \mathrm{s}$

$\rho$ Density, $\mathrm{kg} / \mathrm{m}^{3}$

$\mu$ Viscosity, Pa.s

Responsible Editor: Zeynal Abiddin Erguler

Pingye Guo

Guopingye@ foxmail.com

1 State Key Laboratory for Geomechanics and Deep Underground Engineering, Beijing 100083, China

2 School of Mechanics and Civil Engineering, China University of Mining and Technology, Beijing 100083, China

3 China Institute of Water Resources and Hydropower Research, Beijing 100038, China

\section{Subscripts \\ $r$ rock \\ $f$ airflow}

\section{Introduction}

There are plenty of mine operations conducted in an environment with intense heat and high humidity, due to the high ground temperature. Particularly, in many deep mines, it is necessary to apply the mine cooling system for reducing the high levels of temperature and humidity in the surrounding environment (Sasmito et al. 2015; Guo et al. 2017; Feng et al. 2018). As for the airflow in mine, the most significant source of heat is the surrounding rock, with the fresh rock surface on the working face in particular (Zhang et al. 2017; Maurya et al. 2015). In order to design an optimal mine cooling system, it is essential to understand not only the heat transfer law between the surrounding rock and the airflow in mine but also how the airflow temperature field is distributed (Lu et al. 2017; Wang et al. 2018a, b).

Up to now, there are plenty of published papers focusing on the study of heat transfer between rock and airflow in mine by using theoretical, experimental, or numerical methods, which 
leads to the finding that there are various influencing factors in the heat transfer between the surrounding rock and the airflow, suggesting the complexity of heat transfer mechanism (Gao 2010; Zhang et al. 2016). The heat transfer occurring between the rock and airflow in a mine is diverse, including thermal conduction from rock to airflow, thermal convection between the surrounding wall and airflow, and the thermal radiation from rock to airflow. At the same time, it also includes the heat transfer between surrounding rock and water, water and airflow (Zhao 2014; Bao et al. 2018; Bao and Liu 2019). Therefore, the influencing factors for the thermal environment in a mine include not only temperature, velocity, pressure, and other parameters of airflow but also the temperature, thermal conductivity, and wall roughness of the surrounding rock, as along with such parameters as ventilation time and convective heat transfer coefficient (Zhou et al. 2016; Chen et al. 2019; Li et al. 2016). At present, plenty of studies have been conducted on the temperature of surrounding rock and its unstable heat convection with airflow. Krasnoshtein identified the integration of relations between air and its surrounding rock temperature through Laplace transformation (Krasnoshtein et al. 2007). A three-dimensional unstable local thermal nonequilibrium (LTNE) model has been developed by S. A. Ghoreishi-Madiseh et al., which evaluates thermal storage and thermal transmission rock pits (large broken rock mass) (Ghoreishi-Madiseh et al. 2017). By taking into consideration the coupling of temperature field and moisture fields of the surrounding rock, Zhang constructed another threedimensional numerical model, which was applied to analyze the heat transfer occurring between the airflow and the surrounding rock of tunnel in cold regions (Zhang et al. 2006; Lai et al. 2005; Yan et al. 2017).

In addition to the factors referred to in the above-mentioned literature, the temperature of airflow to the working face is closely associated with the airflow path which is affected by the ventilation systems ( $\mathrm{Su}$ et al. 2017; Hua et al. 2018). As shown in Fig. 1, the central ventilation systems of working face in coalmine are Y-type and U-type. Among them, U-type ventilation is mainly used in traditional longwall mining methods. In recent years, due to the improvement of coal mining methods, Y-type ventilation has been widely adopted in mining operations (Sun et al. 2018; Wang et al. 2018a, $2018 \mathrm{~b})$. In the mining of adjacent working faces, the gobside entry retaining technology can preserve the roadway and increase the ventilation time. Meanwhile, compared with U-type ventilation mode, this mode can prioritize solving the problem of upper-corner gas transfinite on mining face. Moreover, the upper and lower roadways of the working face are all contained in the inlet airflow, which is conducive not only in reducing the concentration of fog-haze and smog (Zou et al. 2017) but also in improving the working environment. Meanwhile, the gob-side entry retaining technology is also used to improve the recovery rate of coal resources.
Nevertheless, there are still few researches focusing on the temperature of airflow in a different ventilation system, especially the comparative study on the distribution of airflow temperature between those with Y-type ventilation and Utype ventilation. Therefore, the focus of this study is placed on analyzing heat convection by conducting numerical simulation between surrounding rock and airflow under Y-type ventilation method. Then, it is compared with the traditional U-type ventilation mode to establish the distribution rule of temperature field in the surrounding rock and airflow.

\section{Model development}

\section{Model of heat transfer between airflow and rock in mine}

As shown in Fig. 2, the heat transfer between the rock and airflow in a mine involves the thermal conduction inside the rock, the thermal convection between the surrounding wall and airflow, and the thermal radiation from rock to airflow. Among them, the thermal radiation from rock to airflow is considered negligible due to a minor. In this model, the surrounding rock temperature field is simplified into a two-dimensional unstable temperature field, and the radiant heat transfer of the surrounding rock wall is not taken into consideration. Differential equation of rock heat conduction is established by Eq. (1), and according to the law of heat convection rule, expressed by Newton's cooling formula, thermal convection between the airflow and rock is solved by Eq. (2), as well as the heat convection of air flow in roadway shall satisfy three laws of thermodynamics, namely, the law of mass conservation, the law of momentum conservation, and the law of energy conservation; flow and heat transfer in the airflow are controlled by Eqs. (3), (4), (5) (Brum et al. 2019). As for the turbulence model of airflow, the RNG $k-\mathcal{E}$ model was employed in this study for its clear advantage in predicting near-wall flow and low Reynolds number flows and excellent performance in both accuracy and efficiency (Liu et al. 2016).

$\frac{D T}{D t}=\alpha \nabla^{2} T$

$Q=\left(T_{r 0}-T_{f}\right) \int_{A_{s}} h d A_{s}$

$\frac{D \rho}{D t}+\rho \operatorname{div} v=0$

$\rho \frac{D v}{D t}=\rho F_{b}-\operatorname{grad} P+\mu \nabla^{2} v$

$\rho \frac{D e}{D t}=-p d i v v+\varphi+d_{i} v(\operatorname{kgrad} T)$ 
Fig. 1 Geometric model of different ventilation models. a The U-type ventilation mode. b The Y-type ventilation mode
Fig. 2 Model of heat transfer between surrounding rock and airflow in mine
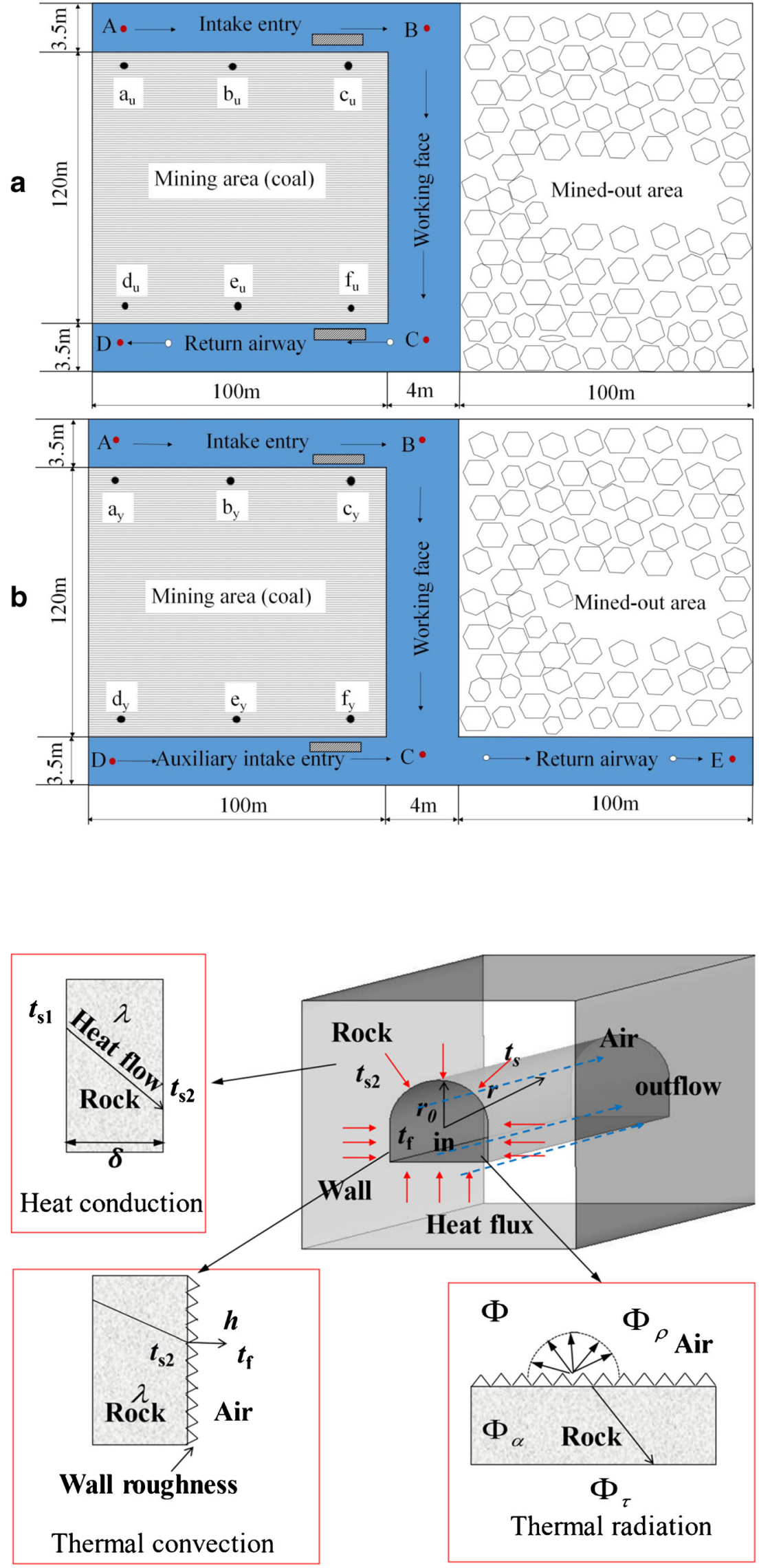


\section{Numerical model}

In this study, the No. 7119 mining face of Zhangshuanglou Coal Mine located in east China was exemplified to conduct analysis of the heat transfer taking place between the surrounding rock and airflow under different ventilation systems with the assistance of commercial CFD software ( $\mathrm{Yu}$ et al. 2015). As shown in Fig. 1, the working face has a tangential length of $120 \mathrm{~m}$, which is the same as the actual one. In the direction of the working face, the area of $200 \mathrm{~m}$ length is selected as the only research area for the convenience of calculation. The length of goaf is $100 \mathrm{~m}$. The effective crosssectional area of the outlet and inlet airflow is $9.8 \mathrm{~m}^{2}$, while that of working face is $12.25 \mathrm{~m}$. The value of porosity is 0.2 .The lithology of the working face mainly includes coal and sandstone at the roof and floor. The distance between the simulated boundary and the roadway is $10 \mathrm{~m}$.

The constructed model is processed with FLUENT numerical simulation software. Calculation area of the original rock temperature is $39^{\circ} \mathrm{C}$; surrounding rock heat dissipation of the main factors in the working face production work sets the wall face temperature as $37^{\circ} \mathrm{C}$, slightly lower than the ground temperature. The nature of the wall is rock, the roughness of the heat exchange surface is set to 0.01 , the roughness constant is 0.5 , it is considered to conform to even distribution, and the wall is set as the coupled heat exchange wall. The initial and boundary conditions of numerical models are detailed in Table 1 and Table 2. In order to understand the temperature variation of the surrounding rock, the measurement points are set to be $90 \mathrm{~m}, 50 \mathrm{~m}$, and $10 \mathrm{~m}$ away from the working face in inlet and outlet roadway under different ventilation system, respectively. Meanwhile, the temperature of airflow at points $\mathrm{A}, \mathrm{B}, \mathrm{C}, \mathrm{D}$, and $\mathrm{E}$ were specifically monitored continuously.

Table 1 Simulate initial conditions

\begin{tabular}{ll}
\hline Name & Reference \\
\hline Original rock temperature, ${ }^{\circ} \mathrm{C}$ & 39 \\
Density of coal, $\mathrm{kg} / \mathrm{m}^{3}$ & 1314 \\
Density of sandstone, $\mathrm{kg} / \mathrm{m}^{3}$ & 2600 \\
Density of air, $\mathrm{kg} / \mathrm{m}^{3}$ & 1.165 \\
Specific heat capacity of coal, $\mathrm{kj} / \mathrm{kg} \cdot{ }^{\circ} \mathrm{C}$ & 1.369 \\
Specific heat capacity of sandstone, $\mathrm{kj} / \mathrm{kg} \cdot{ }^{\circ} \mathrm{C}$ & 8.78 \\
Specific heat capacity of air, $\mathrm{kj} / \mathrm{kg} \cdot{ }^{\circ} \mathrm{C}$ & 1.004 \\
Thermal diffusivity of coal, $\mathrm{m}^{2} / \mathrm{s}$ & $1.59 \times 10^{-7}$ \\
Thermal diffusivity of sandstone, $\mathrm{m}^{2} / \mathrm{s}$ & $1.13 \times 10^{-6}$ \\
Thermal diffusivity of air, $\mathrm{m}^{2} / \mathrm{s}$ & $2.29 \times 10^{-5}$ \\
Thermal conductivity of coal, $\mathrm{w} / \mathrm{m} \cdot \mathrm{K}$ & 0.26 \\
Thermal conductivity of sandstone, $\mathrm{w} / \mathrm{m} \cdot \mathrm{K}$ & 2 \\
Thermal conductivity of air, $\mathrm{w} / \mathrm{m} \cdot \mathrm{K}$ & 0.0287 \\
\hline
\end{tabular}

Table 2 Boundary conditions

\begin{tabular}{cll}
\hline Ventilation way & Boundary conditions & \\
\hline \multirow{2}{*}{ U-type } & Entry condition & Speed entrance \\
& Wind speed & $2 \mathrm{~m} / \mathrm{s}$ \\
& Temperature & $24.5^{\circ} \mathrm{C}$ \\
& Wall roughness & 0.1 \\
& Export conditions & Nature export \\
Y-type & Entry condition & Speed entrance \\
& Main entry airway speed & $1.5 \mathrm{~m} / \mathrm{s}$ \\
& Auxiliary entry wind speed & $0.5 \mathrm{~m} / \mathrm{s}$ \\
& Temperature of main entry airway & $25.1{ }^{\circ} \mathrm{C}$ \\
& Temperature of auxiliary entry wind & $27.1{ }^{\circ} \mathrm{C}$ \\
& Wall roughness & 0.1 \\
& Export conditions & Nature export \\
\hline
\end{tabular}

In order to examine the accuracy of simulation, the airflow temperature as calculated was compared with the measured ones. As shown in Fig. 3, when the temperature of intel airflow is $25.2^{\circ} \mathrm{C}$ and the speed is $2 \mathrm{~m} / \mathrm{s}$ in the working face, the absolute error between the simulated temperature and the real temperature is no greater than $0.6{ }^{\circ} \mathrm{C}$ and the relative error is $2.03 \%$. The calculation results are considered to be broadly consistent with the measurement result.

\section{Result and discussion}

\section{Effect of roughness and ventilation time on heat transfer between rock and airflow}

In addition to the temperature difference between the surrounding rock and airflow, the major influencing factors for

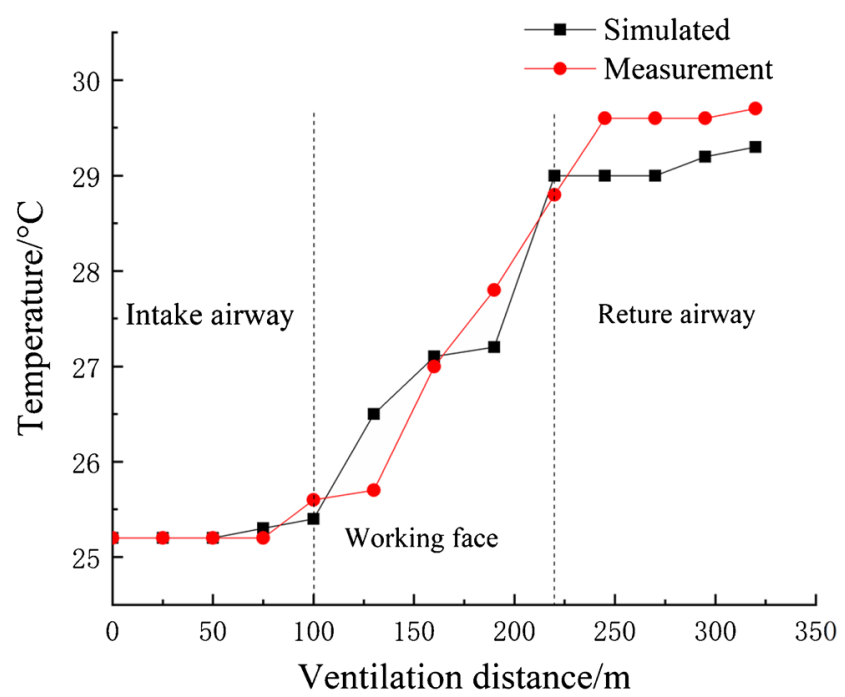

Fig. 3 Comparison of the calculated airflow temperature with those of measured 
the heat transfer between the airflow and rock include the relative roughness of rock-wall and the ventilation time as well. In order to better understand the impact of relative roughness, a 10-m distance from the roadway was applied for the turbulent kinetic energy, while the surface friction coefficient and the effective thermal conductivity with different roughness were calculated. As shown in Fig. 4a, the turbulent kinetic energy at the rock-wall shows a decreasing trend with the distance of the fluid motion. However, as wall roughness is on the rise, the turbulent kinetic energy increases only with the slowdown of momentum. In the meantime, it can be seen from Fig. $4 \mathrm{~b}$ that the friction coefficient of the rock surface rises with the increase of rock roughness. Moreover, an analysis was conducted under different levels of roughness regarding the effective heat transfer coefficient that can be used to describe the heat transfer capacity between rock and airflow. As shown in Fig. 4(c), with the increase of rock-wall roughness, the effective heat transfer coefficient is also on the rise gradually. In summary, the rock-wall roughness could promote the heat transfer between the rock and airflow, and in order to reduce the heat transfer from the surrounding rock to the airflow, the roadway is supposed to be sprayed immediately after the excavation for keeping the wall surface as smooth as possible.

Moreover, the impact of ventilation time on heat transfer was analyzed. Figure 5 shows the temperature field of the surrounding rock with different ventilation time at $50 \mathrm{~m}$ away from the entry roadway. According to Fig. 5, the influence radius of airflow on the temperature of the surrounding rock increases with the extension of the ventilation time. The influence radius is $3.25 \mathrm{~m}$ after continuous ventilation for 1 day, $5.45 \mathrm{~m}$ after continuous ventilation for 20 days, and $6.39 \mathrm{~m}$ after continuous ventilation for 40 days, respectively. Meanwhile, as the ventilation time extended, the temperature of airflow in the cross-section of the roadway tends to be equal. During the initial period of ventilation, the temperature difference between the airflow and the surrounding rock-wall is relatively significant, and there are evident heat convection and a wide range of temperature decrease for the surrounding rock near the wall. As the time of ventilation extended, the temperature of the surrounding rock drops at a slow pace, the influence radius of the surrounding rock reaches to the depth, but the pace of expansion gradually slows down. When the time of ventilation is sufficient, there is no notable change in wall temperature, while the impact of ventilation time on the temperature field of the surrounding rock and influence radius diminishes on a continued basis.

\section{Effect of ventilation system on the temperature of surrounding rock}

In order to compare the temperature of surrounding rock between different ventilation systems, the influence radius of
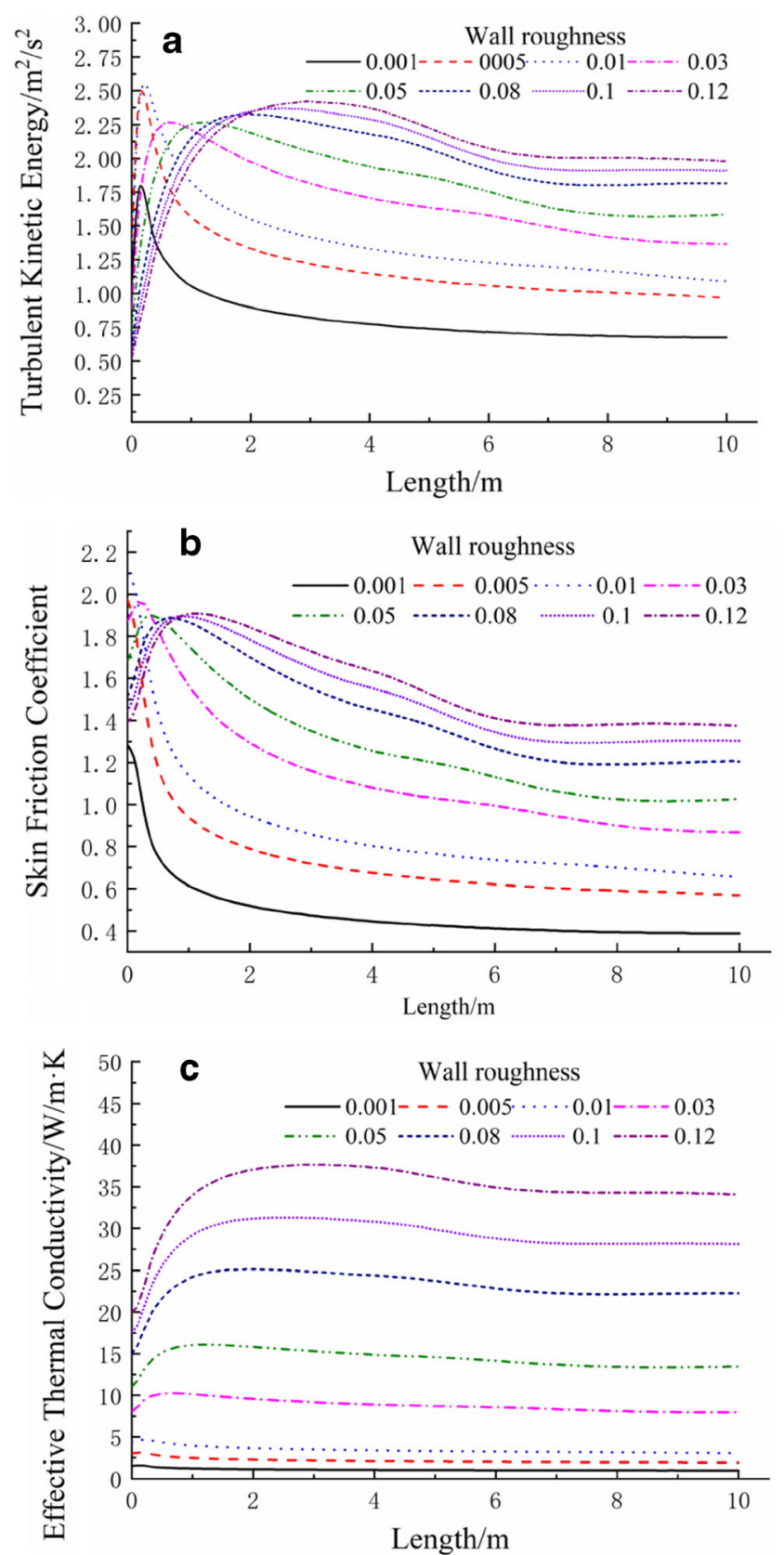

Fig. 4 Effect of rock-wall roughness on heat transfer between rock and airflow: a Turbulent kinetic energy of rock surface with different roughness. b Skin friction coefficient distribution with different roughness. c Effective thermal conductivity distribution with different roughness

airflow on the temperature of the rock at each measurement point (see Fig. 1) is shown in Fig. 6. As shown in Fig. 6 a, the influence radius of airflow with U-type ventilation is greater than that with Y-type ventilation in inlet roadway. After 1 month of ventilation, the average influence radius with $\mathrm{U}$ type and Y-type system is found to be $6.38 \mathrm{~m}$ and $6.22 \mathrm{~m}$, respectively, which is attributed to the different wind speeds at this point under different ventilation modes. In the U-type 

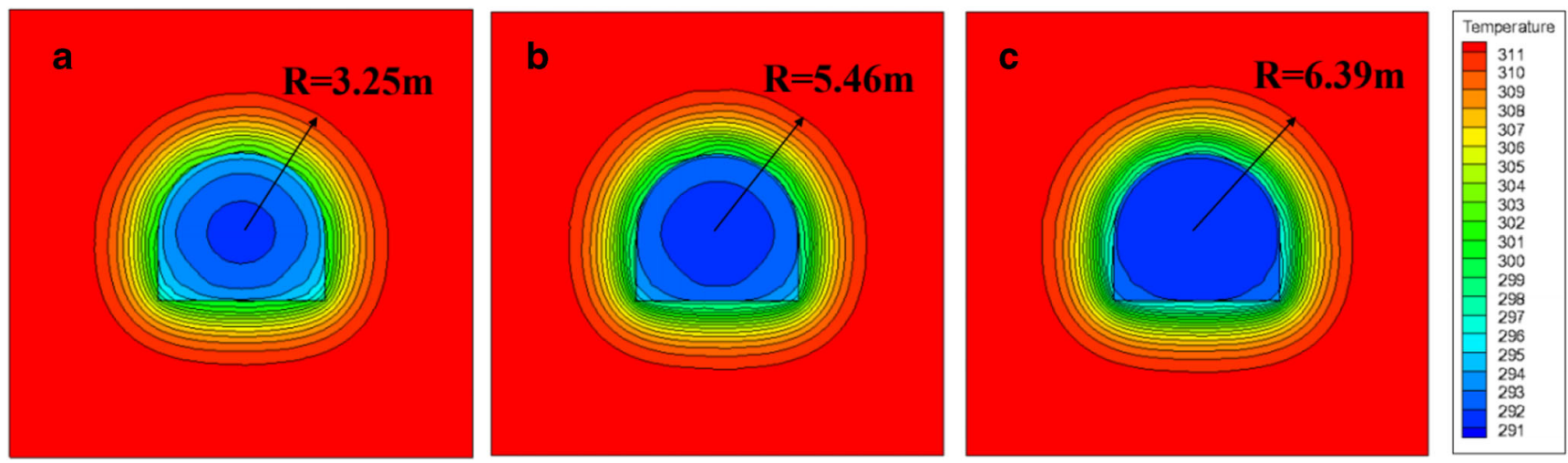

Fig. 5 Variation of temperature of surrounding rock with different ventilation time. a The 1st day. b The 20th day. c The 40th day

system, the total volume of airflow in working face enters through one inlet roadway. However, in the Y-type system, one quarter of the total airflow enters another inlet roadway. For the point $\mathrm{d}$, e, and $\mathrm{f}$, after 1 month of ventilation, the
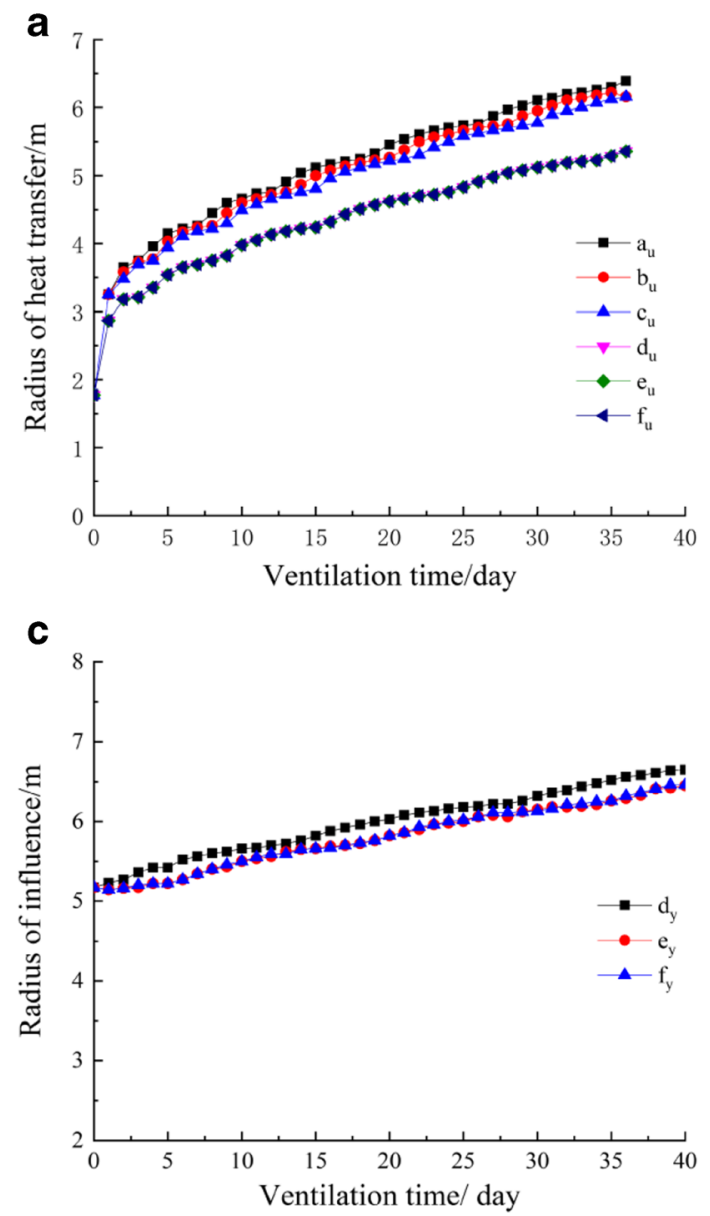

Fig. 6 Temperature field characteristics of the surrounding rock with different ventilation model. a Temperature field characteristics of the surrounding rock with U-type ventilation model. b Temperature field characteristics of the surrounding rock with Y-type ventilation model. c influence radius of the airflow with U-type and Y-type ventilation system is shown to be $5.35 \mathrm{~m}$ and $5.17 \mathrm{~m}$, respectively.

The surrounding rock temperature field of the inlet airway in the adjacent mining face with U-type ventilation will be immune from the impact of the previous working face due

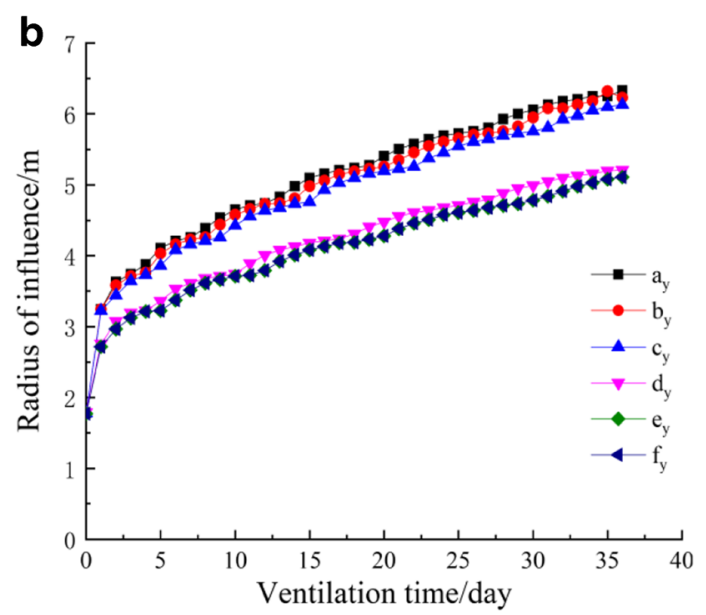

d

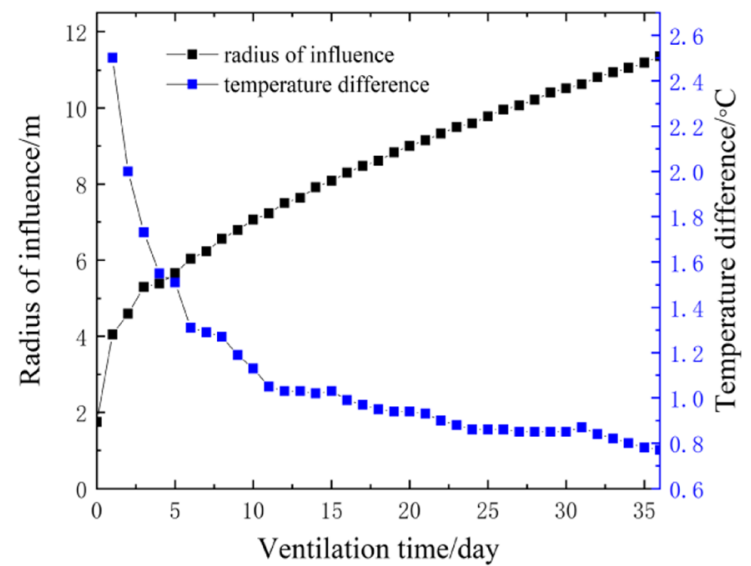

Temperature field characteristics of the surrounding rock with Y-type ventilation model in the next working face. $\mathbf{d}$ Temperature field characteristics of the surrounding rock in goaf with Y-type ventilation model 

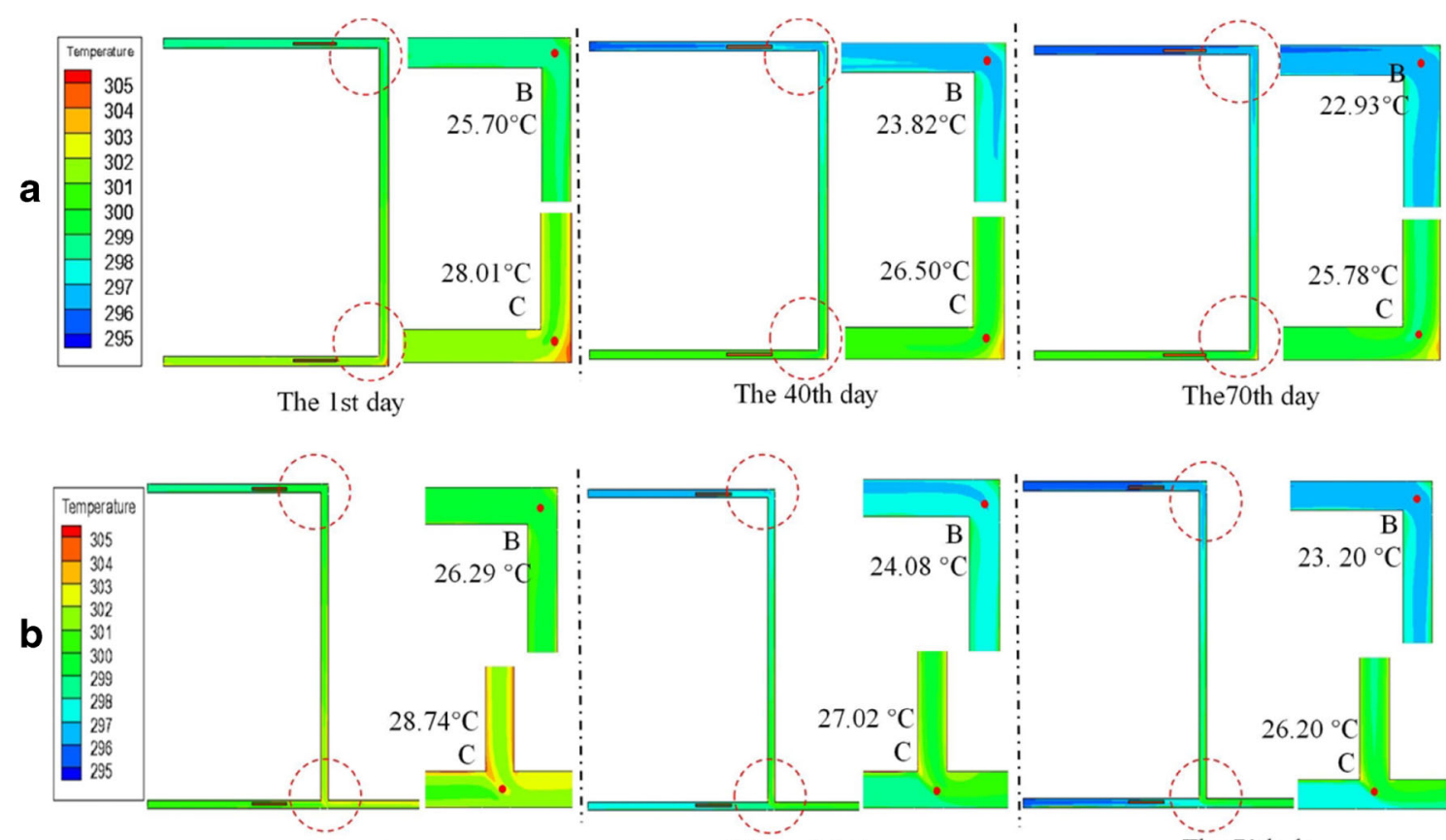

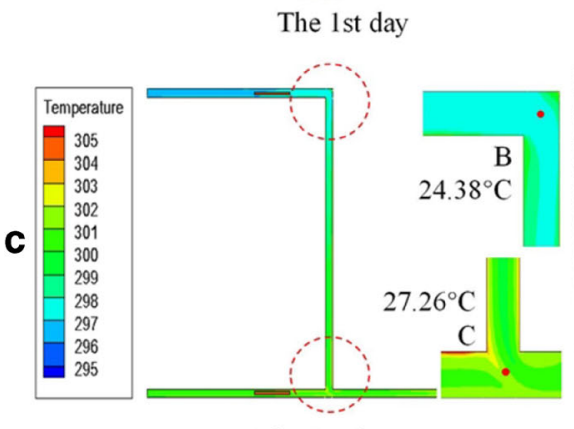

The 1st day
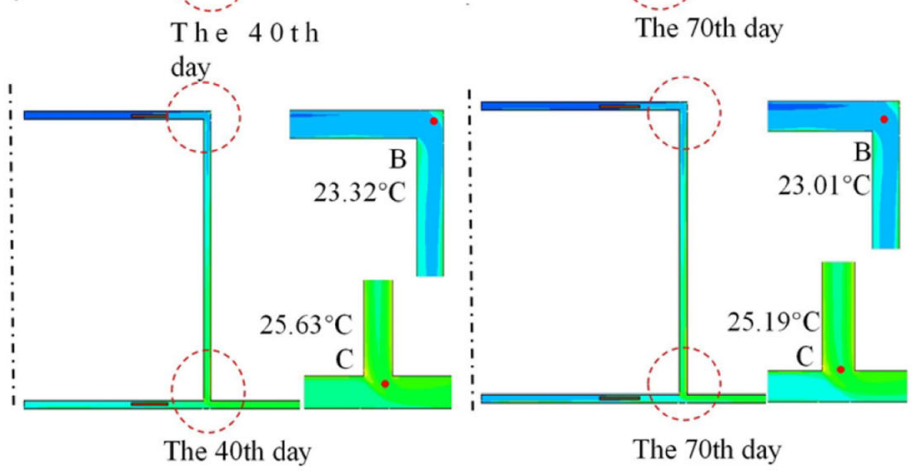

Fig. 7 Characteristics of airflow temperature field in working face under different ventilation models. a Wind temperature flied distribution of Utype ventilation in the first working face. $\mathbf{b}$ Wind temperature flied

to the existence of reserved coal pillars. In the Y-type system, however, the auxiliary inlet and return airway will be reused as the inlet airway of the next adjacent working face. When the adjacent mining face enters into operation, the surrounding rock has been cooled for a long time. Therefore, as shown in Fig. 6b, the influence radius of airflow increases from 5.17 to $6.65 \mathrm{~m}$ during mining of the current working face.

The airflow in Y-type ventilation working face and that airflow in auxiliary inlet airway converge at point $\mathrm{C}$ in the lower corner of the return airway and flow out through the return airway. In the return airway, one side is goaf, which is composed of the roof rock caved, and shows different characteristics of heat transfer different from those of the undisturbed surrounding rock. Therefore, after 1 month of ventilation, the influence radius of airflow in goaf reaches $10.52 \mathrm{~m}$. As the temperature difference between the surrounding rock and the rock-airway interface is reduced gradually, the heat convection effect ceases to be significant, and the dropping scale of the surrounding rock distribution of Y-type ventilation in the first working face. $\mathbf{c}$ Wind temperature flied distribution of Y-type ventilation in adjacent working face

temperature. As shown in Fig. 6 c, with the extension of ventilation time, the temperature difference between the near-wall airflow and the surrounding rock in goaf is reduced, and the influence radius in goaf increases at a slow pace until it becomes constant.

\section{Effect of ventilation system on the temperature of the airflow}

The airflow temperature field of the working face under different ventilation systems is shown in Fig. 7. Firstly, the airflow temperature field of the first working face was analyzed under different ventilation systems. As shown in Fig. 7 a, the maximum temperature of airflow under U-type ventilation system is $28.01{ }^{\circ} \mathrm{C}$ at point $\mathrm{C}$ after continuous ventilation for 1 day, $26.50{ }^{\circ} \mathrm{C}$ after continuous ventilation for 40 days, and $25.78{ }^{\circ} \mathrm{C}$ after continuous ventilation for 70 days, respectively. Compared with U-type ventilation system, the ventilation amount in inlet 

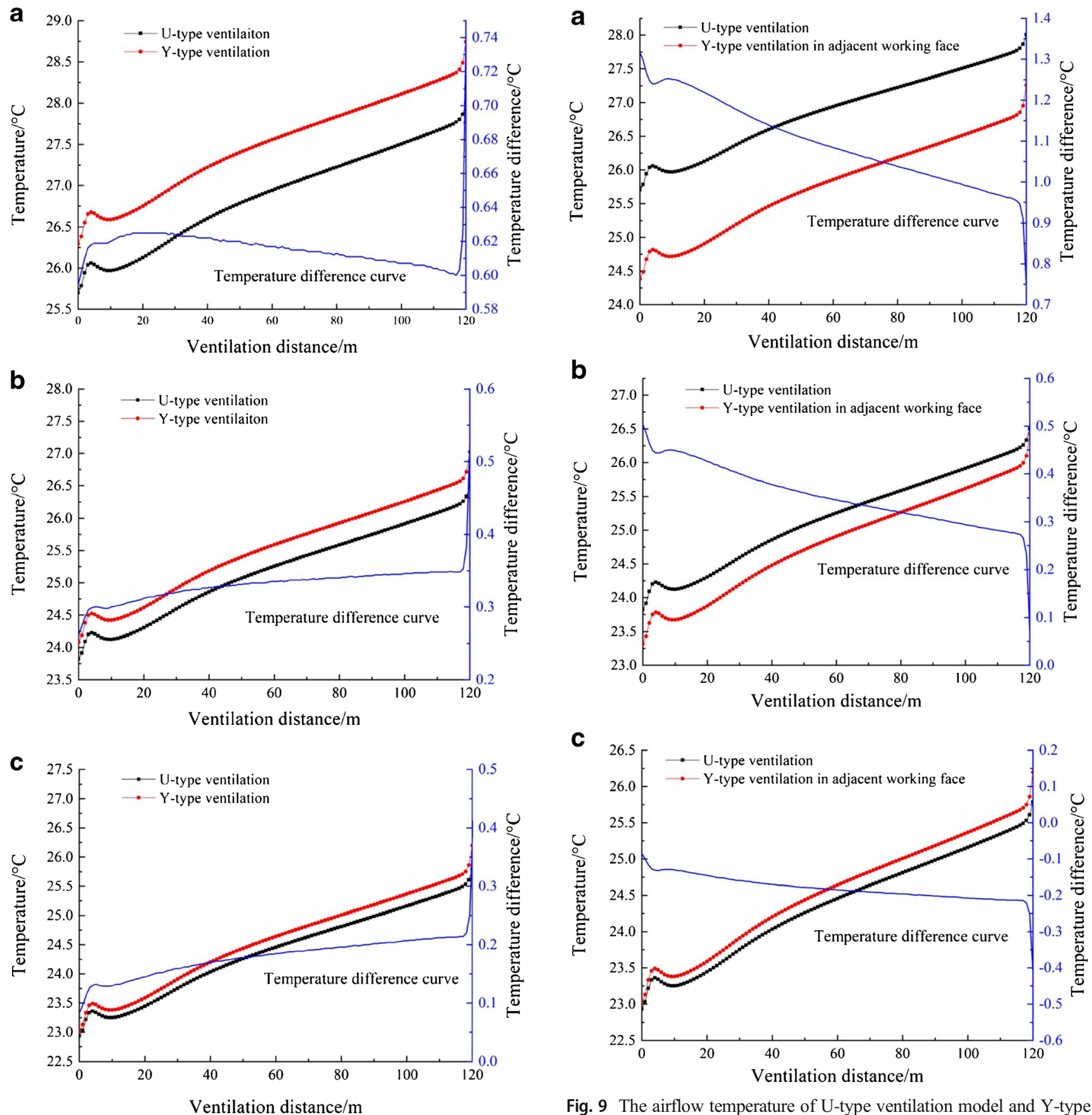

Fig. 9 The airflow temperature of U-type ventilation model and Y-type ventilation model in the adjacent working face. a The 1st day. b The 40th day. c The 70th day

Fig. 8 The airflow temperature of U-type ventilation model and Y-type ventilation model in the first working face. a The 1st day. b The 40th day. c The 70th day

airway is smaller, and the maximum temperature of the mining face is $28.74{ }^{\circ} \mathrm{C}$ after 1 day, $27.02{ }^{\circ} \mathrm{C}$ after 40 days, and $26.2^{\circ} \mathrm{C}$ after 70 days, respectively, as shown in Fig. 7 b. In the meantime, the airflow temperature of the next adjacent working face was also analyzed. In the U-type ventilation system, the temperature field of the next adjacent working face and the first working face remains unchanged. However, in the Y-type ventilation system, the airflow temperature of the next adjacent working face is

lower compared with the first working face. As shown in Fig. $7 \mathrm{c}$, in comparison with the first mining face, the maximum temperature of the next adjacent working face after ventilation for 1 day, 40 days, and 70 days declines to 27.26, 25.63, and $25.19{ }^{\circ} \mathrm{C}$, respectively, which is primarily attributed to the cooling effect of pre-ventilation on the surrounding rock of the intake airway. In the Y-type ventilation system, the auxiliary inlet and return airway of the first working face are taken as the intake 
airway when the next adjacent working face is mined, and the long-term cooling during the mining of the first working face will make the temperature of the surrounding rock, as shown in Fig. $6 \mathrm{c}$.

As shown in Fig. 8, the temperature of the airflow in the first working face is lower than in the Y-type system. As ventilation proceeds, the roadway is cooled gradually, and the temperature difference between Y-type and U-type ventilation is reduced progressively, from 0.62 in Fig. 8 a to $0.2{ }^{\circ} \mathrm{C}$ in Fig. $8 \mathrm{c}$. Nevertheless, as for the next adjacent working face, it can be seen from Fig. 9 that the temperature of airflow with a Y-type ventilation system is lower than that with U-type ventilation.

Compared with U-type ventilation method, after 1 day of ventilation, the temperature of the adjacent face of Y-type is lower than that of U-type with the difference ranging between 0.8 and $1.3{ }^{\circ} \mathrm{C}$. After 40 days, the difference ranges from 0.3 to $0.5^{\circ} \mathrm{C}$, as shown in Fig. 9 b. After 70 days of ventilation, the temperature in the roadway is basically consistent under the two ventilation modes, and the cooling effect remains the same, as shown in Fig. 9 c.

\section{Conclusion}

1) In this study. The heat transfer model between the airflow and the surrounding rock in the coalmine is proposed. Through the analysis of the influencing factors in the heat transfer of the surrounding rock and airflow, it is found out that the wall roughness of the surrounding rock is conducive in enhancing the heat transfer between the surrounding rock and airflow.

2) In the initial stage of ventilation, the amount of heat transfer between airflow, and surrounding rock is significant; the pace of change in the surrounding rock temperature is greater, and the expansion of heat regulating circle is faster. With the increase of ventilation time, the radius of the control heat circle gradually expands into the deep area of the surrounding rock. With the increase of wind temperature in roadway, when the wall temperature of surrounding rock no longer changes significantly, the influence of ventilation time on the control heat circle of the surrounding rock will be diminishing. Therefore, when mining is conducted at the high temperatures, it is essential for the surface of the newly excavated surrounding rock to be sprayed promptly to prevent heat transfer to airflow.

3) Through the comparison heat transfer between the airflow and surrounding rock in the working face under two ventilation modes, it is discovered that the airflow temperature under the U-type ventilation condition is lower than that under the Y-type condition in the first working face. As for the next adjacent working face, however, the Y- type ventilation system is more conducive in reducing the temperature of the airflow. Therefore, for the whole mine, the choice of the Y-type ventilation is more conducive to improving its thermal environment.

Acknowledgments The authors wish to thank the reviewers for careful and constructive suggestions.

Author contributions All the authors contributed to this paper. Pingye Guo and Yi Su conceived and designed the research. Dongyang Pang performed the field experiment guidance. Yanwei Wang and Zhibiao Guo perform the data analysis and processing.

Funding information Supported by the Yue Qi Young Scholar Program (China University of Mining \& Technology (Beijing)), the NSFC (41402273; 41502264), and the Fundamental Research Funds for the Central Universities (2010QL06).

\section{Compliance with ethical standards}

Conflict of interest The authors declare no conflict of interest.

Open Access This article is licensed under a Creative Commons Attribution 4.0 International License, which permits use, sharing, adaptation, distribution and reproduction in any medium or format, as long as you give appropriate credit to the original author(s) and the source, provide a link to the Creative Commons licence, and indicate if changes were made. The images or other third party material in this article are included in the article's Creative Commons licence, unless indicated otherwise in a credit line to the material. If material is not included in the article's Creative Commons licence and your intended use is not permitted by statutory regulation or exceeds the permitted use, you will need to obtain permission directly from the copyright holder. To view a copy of this licence, visit http://creativecommons.org/licenses/by/4.0/.

\section{References}

Bao T, Liu L (2019) Thermohaline stratification modeling in mine water via double-diffusive convection for geothermal energy recovery from flooded mines. Applied Energy 237:566-580. https://doi.org/ 10.1016/j.apenergy.2019.01.049

Bao T, Liu Z, Meldrum J, Green C, Xue PF, Stan V (2018) Field tests and multiphysics analysis of a flooded shaft for geothermal applications with mine water. Energy Conversion and Management:169. https:// doi.org/10.1016/j.enconman.2018.05.065

Brum RS, Ramalho JVA, Rodrigues MK, Rocha LAO, Isoldi LA, Dos Santos ED (2019) Design evaluation of earth-air heat exchangers with multiple ducts. Renew Energy 135:1371-1385. https://doi.org/ 10.1016/j.renene.2018.09.063

Chen L, Li J, Han F, Zhang Y, Liu L, Zhang B (2019) Analysis of the thermal characteristics of surrounding rock in deep underground space. Advances in Civil Engineering 2019:1-9. https://doi.org/10. $1155 / 2019 / 2130943$

Feng XP, Jia Z, Liang H, Wang Z, Wang B, Jiang X, Cao H, Sun X (2018) A full air cooling and heating system based on mine water source. Appl Therm Eng 145:610-617. https://doi.org/10.1016/j. applthermaleng.2018.09.047

Gao J (2010) Numerical prediction of thermal environmental conditions in locally ventilated working places. In 2010 second international conference on computer engineering and applications. 2010 Second 
international conference on computer engineering and applications, Bali Island, Indonesia, 2010/3/19-2010/3/21; IEEE, 2010-2010; pp 436-442. ISBN 978-1-4244-6079-3

Ghoreishi-Madiseh SA, Sasmito AP, Hassani FP, Amiri L (2017) Performance evaluation of large scale rock-pit seasonal thermal energy storage for application in underground mine ventilation. Appl Energy 185:1940-1947. https://doi.org/10.1016/j.apenergy.2016. 01.062

Guo PY, He M, Zheng L, Zhang N (2017) A geothermal recycling system for cooling and heating in deep mines. Appl Therm Eng 116:833839. https://doi.org/10.1016/j.applthermaleng.2017.01.116

Hua Y, Nie W, Cai P, Liu YH, Peng HT, Liu Q (2018) Pattern characterization concerning spatial and temporal evolution of dust pollution associated with two typical ventilation methods at fully mechanized excavation faces in rock tunnels. Powder Technol 334:117131. https://doi.org/10.1016/j.powtec.2018.04.059

Krasnoshtein AE, Kazakov BP, Shalimov AV (2007) Modeling phenomena of non-stationary heat exchange between mine air and a rock mass. J Min Sci 43:522-529

Lai YM, Zhang XF, Yu WB, Zhang SJ, Liu ZQ, Xiao JZ (2005) Threedimensional nonlinear analysis for the coupled problem of the heat transfer of the surrounding rock and the heat convection between the air and the surrounding rock in cold-region tunnel. Tunn Undergr Space Technol 20:323-332. https://doi.org/10.1016/j.tust.2004.12. 004

Li A, Yang C, Ren T (2016) Modeling and parametric studies for convective heat transfer in large, long and rough circular cross-sectional underground tunnels. Energy and Buildings 127:259-267. https:// doi.org/10.1016/j.enbuild.2016.05.088

Liu Y, Wang S, Deng Y, Ma W, Ma Y (2016) Numerical simulation and experimental study on ventilation system for powerhouses of deep underground hydropower stations. Appl Therm Eng 105:151-158. https://doi.org/10.1016/j.applthermaleng.2016.05.101

Lu Y, Guan Z, Hooman K, Parulekar PS (2017) An investigation on cooling performance of air-cooled heat exchangers used in coal seam gas production. Heat Transfer Engineering 38:1073-1088. https://doi.org/10.1080/01457632.2016.1217039

Maurya T, Karena K, Vardhan H, Aruna M, Raj MG (2015) Effect of heat on underground mine workers. Procedia Earth and Planetary Science 11:491-498. https://doi.org/10.1016/j.proeps.2015.06.049

Sasmito AP, Kurnia JC, Birgersson E, Mujumdar AS (2015) Computational evaluation of thermal management strategies in an underground mine. Appl Therm Eng 90:1144-1150. https://doi.org/ 10.1016/j.applthermaleng.2015.01.062

Su HT, Zhou FB, Song XL, Qiang ZY (2017) Risk analysis of spontaneous coal combustion in steeply inclined longwall gobs using a scaled-down experimental set-up. Process Saf Environ Prot 111:112. doi:https://doi.org/10.1016/j.psep.2017.06.001, 1

Sun XM, Gan L, Zhao CW, Tang JQ, He MC, Peng S, Miao CY (2018) Numerical investigation of gob-side entry retaining through precut overhanging hard roof to control rockburst. Advances in Civil Engineering 2018:1-10. https://doi.org/10.1155/2018/8685427

Wang M, Liu L, Chen L, Zhang X, Zhang B, Ji C (2018a) Cold load and storage functional backfill for cooling deep mine. Advances in Civil Engineering 2018:1-8. https://doi.org/10.1155/2018/5435214

Wang Q, He MC, Yang J, Gao H, Jiang B, Yu H (2018b) Study of a nopillar mining technique with automatically formed gob-side entry retaining for longwall mining in coal mines. Int J Rock Mech Min Sci 110:1-8. https://doi.org/10.1016/j.ijrmms.2018.07.005

Yan QX, Li BJ, Zhang YY, Yan J, Zhang C (2017) Numerical investigation of heat-insulating layers in a cold region tunnel, taking into account airflow and heat transfer. Appl Sci 7:679. https://doi.org/10. 3390/app7070679

Yu Y, Cao L, Li X, Shi W, Wu J (2015) Modeling of heat and mass transfer of tunnel ventilation in hydropower station. Appl Therm Eng 90:45-53. https://doi.org/10.1016/j.applthermaleng.2015.06. 097

Zhang XF, Yu WB, Wang C, Liu ZQ (2006) Three-dimensional nonlinear analysis of coupled problem of heat transfer in the surrounding rock and heat convection between the air and the surrounding rock in the Fenghuo mountain tunnel. Cold Reg Sci Technol 44:38-51. https://doi.org/10.1016/j.coldregions.2005.07.002

Zhang Y, Wan Z, Gu B, Zhou C (2016) An experimental investigation of transient heat transfer in surrounding rock mass of high geothermal roadway. Therm Sci 20:2149-2158. https://doi.org/10.2298/ TSCI151017053Z

Zhang Y, Wan ZJ, Gu B, Zhou CB, Cheng JY (2017) Unsteady temperature field of surrounding rock mass in high geothermal roadway during mechanical ventilation. J Cent South Univ 24:374-381. https://doi.org/10.1007/s11771-017-3439-3

Zhao ZH (2014) On the heat transfer coefficient between rock fracture walls and flowing fluid. Computers and Geotechnics 59:105-111. https://doi.org/10.1016/j.compgeo.2014.03.002

Zhou X, Zeng Y, Fan L (2016) Temperature field analysis of a coldregion railway tunnel considering mechanical and train-induced ventilation effects. Appl Therm Eng 100:114-124. https://doi.org/ 10.1016/j.applthermaleng.2016.01.070

Zou SH, Li KQ, Han QY, Yu CW (2017) Numerical simulation of the dynamic formation process of fog-haze and smog in transport tunnels of a hot mine. Indoor and Built Environment 26:1062-1069. https://doi.org/10.1177/1420326X16666621 